\title{
Cells spreading on Micro-fabricated Silica Thin film Coatings
}

\author{
A. Pelaez-Vargas ${ }^{*}$, N. Ferrell ${ }^{* *}$, M. H. Fernandes ${ }^{* * *}$, D. Hansford ${ }^{* *}$ and F. J. Monteiro* \\ * INEB - Instituto de Engenharia Biomédica, Divisão de Biomateriais, Universidade do Porto, \\ Portugal and Departamento de Engenharia Metalúrgica e Materiais, FEUP - Faculdade de \\ Engenharia, Universidade do Porto, Portugal. \\ ** Department of Biomedical Engineering, Ohio State University, Columbus (Ohio) USA. \\ ${ }^{* * * *}$ Laboratório de Farmacologia e Biocompatibilidade Celular, Faculdade de Medicina Dentária, \\ Universidade do Porto, Portugal. \\ fjmont@ineb.up.pt
}

From a biomaterials perspective, it is now understood that success in the osseointegration of a dental implant is conditioned by its "macro", "micro" and "nano" scale features. Macro-scale roughness is necessary to improve primary stabilization in the post-surgical phase inducing a peri-implant thin fibrous layer. However, the more complex process in the true cell-material interaction is dependent on micro and nano scale phenomena [1]. There is clear evidence that cell adhesion, proliferation, organization and phenotype are modulated at the micro-scale and that protein absorption is fundamentally a process conditioned at nano-scale [2].

Hypothetically, a biologically friendlier surface may be produced using soft lithography and sol-gel techniques to obtain micro-structured coatings for dental applications. The purpose of this work was to compare spreading of Human Bone Marrow (HBM) cells on silica thin films produced by sol-gel, processed with two different surface features: micro-pillars patterns (MPPS) and flat surfaces (FS).

Sol-gel processing was used to produce hybrid silica sols resulting from acid catalysis in a single stage. Tetraethylorthosilicate (TEOS, Aldrich) and Methyltriethoxisilane (MTES, Aldrich) were selected as silica precursors for the sol, while alcohol was used as a solvent and nitric acid and acetic acid were used as catalysts. Spin Coating technique was chosen to apply $\mathrm{SiO}_{2}$ flat coatings on microscope glass slides as model substrates.

Photolithography was used to produce master pattern with micro-scale dimensions. A polydimethylsiloxane (PDMS) molding was obtained from the masters by uniformly mixing PDMS (Silastic T-2, Dow Corning, USA) with a curing agent, pouring the mixture onto the masters, degassing, and curing [3]. A molding was used to stamp $\mathrm{SiO}_{2}$ coatings produced by a sol-gel process. The coatings were sintered using a thermal cycle that included heating up to $450^{\circ} \mathrm{C}$ at a rate of $20^{\circ} \mathrm{C} / \mathrm{min}$, a plateau at $450^{\circ} \mathrm{C}$ for $30 \mathrm{~min}$ and cooling in air using an elevator furnace, followed by autoclave sterilization.

Human Bone Marrow (HBM) was obtained from patients undergoing orthopaedic surgery procedures. Primary cultures of Human Bone marrow was cultured under a standardized protocol and maintained for 10/15 days till near confluence, when adherent cells were enzymatically released. Flat and micro-patterned coatings were cultured with HBM cells ( $3^{\text {th }}$ and $5^{\text {th }}$ passage), under the same conditions of Primary cultures for $4 \mathrm{~h}$ and $24 \mathrm{~h}$. Samples were prepared according to the following sequence: Three cultured samples per group were washed with PBS, fixed using $1.5 \%$ glutaraldehide, dehydrated in graded alcohol solutions, gold sputtered. Cell morphology and orientation were evaluated by SEM. 


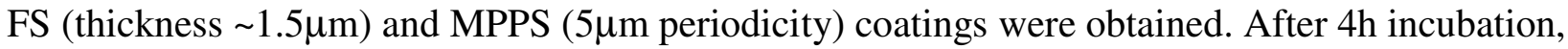
HBM cells exhibited well defined morphology with an incipient spreading on the structured surface of MPPS silica coating (Fig. 1). After 24h incubation, cells had two typical morphologic features: (a) Elliptic slimmer shape, with a long cytoplasmatic extensions growing on the top of pillars or inside the valleys between adjacent pillars (Fig. 2) and (b) butterfly shape with multidirectional spreading on FS silica coatings. MPPS surfaces didn't show a clear control over HBM cell orientation. Previous studies on HBM cells behaviour on line shaped micro-patterned coatings had shown contradictory results, with a marked controlled cell orientation being present [4].

\section{References}

[1] B. D. Boyan , C. H. Lohmann, D. D. Dean, V. L. Sylvia, D. L. Cochran, Z. Schwartz, Ann Rev Mater Res, 31(1) (2001) 357.

[2] A. Wennerberg, T. Albrektsson, B. Andersson, JJ Krol, Clin Oral Impl Res, 6(1) (1995) 24.

[3] D. Gallego, N. Ferrell, Y Sun, Hansford D., Mater Sci Eng C, 28(3) (2008) 353-358.

[4]A. Pelaez-Vargas, N. Ferrell, M.H. Fernandes, D. Hansford, Monteiro F. J., Key Eng Mater, 396398(1) (2009) 303.

The authors acknowledge the support of Portuguese Science and Technology Foundation (Scholarship FCT/SFRH/BD/36220/2007).

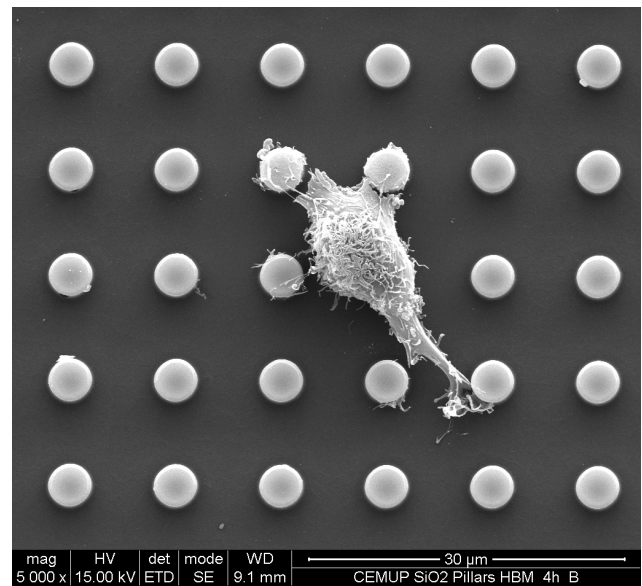

Fig. 2. SEM images (SE mode, $10 \mathrm{kV})$ of HBM cells on Silica coatings after $24 \mathrm{~h}$ incubation. General view showed include a multipillar structured silica surface where adherent cells adopted a slimmer shape with long cytoplasmatic extensions. In the Upper-Left close view HBM cell with a butterfly shape and multidirectional spreading on Flat Silica surface produced by Spin Coating.
Fig. 1. SEM images (SE mode, $15 \mathrm{kV}$ ) of HBM cells on MPPS Silica coatings after $4 \mathrm{~h}$ incubation. Typical cell showing a rounded shape with filipodium and incipient cytoplasmatic extensions attached in the top and base of pillars.

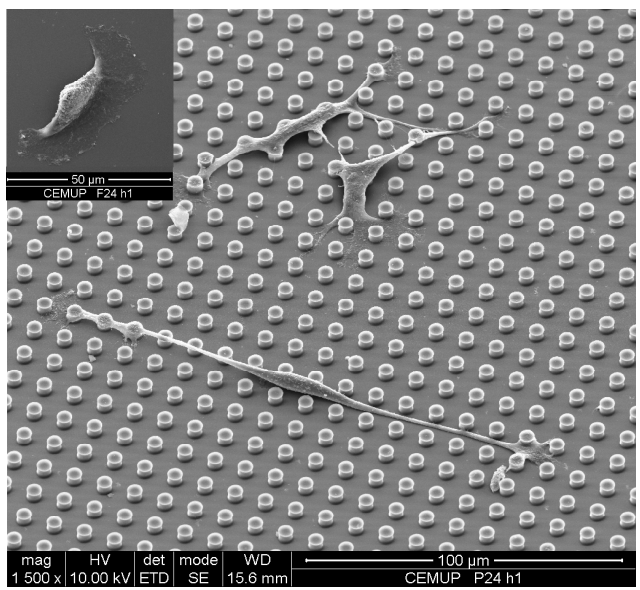

